\title{
RESEARCH
}

Open Access

\section{Best implant choice for coracoid graft fixation during the Latarjet procedure depends on patients' morphometric considerations}

\author{
Achilleas Boutsiadis ${ }^{1}$, Ioannis Bampis ${ }^{1}$, John Swan ${ }^{2}$ and Johannes Barth ${ }^{2^{*}}$
}

\begin{abstract}
Purpose: To assess the anthropometric dimensions of the coracoid process and the glenoid articular surface and to determine possible implications with the different commercially available Latarjet fixation techniques.

Methods: In a total of 101 skeletal scapulae the glenoid length (GL), the glenoid width (GW), the coracoid length $(\mathrm{CL})$, the coracoid width $(\mathrm{CW})$ and the coracoid thickness $(\mathrm{CTh})$ were measured. In order to assess the ability of the transferred coracoid to restore the glenoid anatomy we created a hypothetical model of 10\%, 15\%,20\%, 25\% and $30 \%$ glenoid bone loss. We analyzed four common surgical fixation techniques for the Latarjet procedure $(4.5 \mathrm{~mm}$ screws, $3.75 \mathrm{~mm}$ screws, $3.5 \mathrm{~mm}$ screws, and $2.8 \mathrm{~mm}$ button). The distances from the superior-inferior and mediolateral limits of the coracoid using the four different fixation methods were calculated. We hypothesized that the "safe distance" between the implant and the coracoid osteotomy should be at least equal to the diameter of the implant.

Results: The intra and inter-observer reliability tests were almost perfect for all measurements. The mean GH was $36.8 \pm 2.5 \mathrm{~mm}$, the GW $26.4 \pm 2.2 \mathrm{~mm}$, the $\mathrm{CL} 23.9 \pm 3 \mathrm{~mm}$, the CW $13.6 \pm 2 . \mathrm{mm}$, and the mean CTh was $8.7 \pm 1.3$ $\mathrm{mm}$. The CL was $<25 \mathrm{~mm}$ in $46 \%$ of the cases. In cases with $25 \%$ and $30 \%$ bone loss, the coracoid graft restored the glenoid anatomy in $96 \%$ and $79.2 \%$ of the cases. With the use of the $4.5 \mathrm{~mm}$ screws the "safe distance" was present in $56 \%$ of the cases, with the $3.75 \mathrm{~mm}$ screws in $85 \%$, with the $3.5 \mathrm{~mm}$ screws in $87 \%$, and with the $2.8 \mathrm{~mm}$ button in $98 \%$ of the cases. The distance from the medio-lateral limit of the coracoid could be significantly increased (up to $9 \mathrm{~mm}$ ) when smaller-button implants are used.

Conclusions: The coracoid graft could not always restore glenoid defects of 30\%. Larger implants could be positioned too close to the osteotomy and the "medio-lateral offset" of the coracoid could be increased with smaller implants.
\end{abstract}

Keywords: Coracoid dimensions, Glenoid dimensions, Latarjet technique, Latarjet implants, Glenoid bone loss

\footnotetext{
* Correspondence: jrhbarth@yahoo.fr

${ }^{2}$ Department of Orthopaedic Surgery, Centre Osteoarticulaire des Cèdres,

Parc sud galaxie, 5 Rue Des Tropiques, 38130 Echirolles, Grenoble, France

Full list of author information is available at the end of the article
}

\section{Springer Open}

(c) The Author(s). 2020 Open Access This article is licensed under a Creative Commons Attribution 4.0 International License, which permits use, sharing, adaptation, distribution and reproduction in any medium or format, as long as you give appropriate credit to the original author(s) and the source, provide a link to the Creative Commons licence, and indicate if changes were made. The images or other third party material in this article are included in the article's Creative Commons licence, unless indicated otherwise in a credit line to the material. If material is not included in the article's Creative Commons licence and your intended use is not permitted by statutory regulation or exceeds the permitted use, you will need to obtain permission directly from the copyright holder. To view a copy of this licence, visit http://creativecommons.org/licenses/by/4.0/. 


\section{Introduction}

The glenohumeral joint is the least stable joint in the human body, and is prone to recurrent anterior instability. Anterior shoulder instability is disabling and has the highest incidence in young males, and the preferred treatment is surgical [1]. The two commonest surgical treatments for anterior shoulder instability are the arthroscopic Bankart repair and the Latarjet procedure [2].

The Latarjet procedure was first described in 1954 [3], and the advantage of this technique is the triple blocking stabilizing mechanism proposed by Patte and Debeyre: a) the "bone block effect", b) the "ligament effect" of the repair of the capsule to the stump of the coracoacromial ligament, and c) the "sling effect" that is produced by the dynamic interaction between the subscapularis muscle and the conjoint tendon [4]. Biomechanical studies have shown that the dynamic "sling effect" may be the most important stabilizing factor [5]. Recent studies have reported that the Latarjet procedure may be indicated even in cases with minimal glenoid bone loss, and could have good to excellent long term results [2, 6-8]. However, several reports highlighted the completely different treatment approach of the French surgeons, who in $72 \%$ of cases prefer the Latarjet procedure as the primary treatment option, while other international surgeons preferred the Bankart repair in $90 \%$ of primary cases [9]. A possible explanation for this observation may be the significant technical difficulties and the possible complications of the original Latarjet technique $[10,11]$. Some of the complications, such as coracoid graft fracture or postoperative recurrence could be related to specific osseous anatomy of the glenoid and coracoid process [10]. For example, when performing the open Latarjet procedure recommended by Walch, a coracoid bone graft length of more than $25 \mathrm{~mm}$ is necessary to enable the safe insertion of two $4.5 \mathrm{~mm}$ screws [11] or when the glenoid erosion is excessive, a "congruent arc" technique is necessary [12].

\section{Purpose}

The purpose of this study was, firstly to assess the anthropometric dimensions of the coracoid process and the glenoid articular surface in the young Greek population and secondly, to determine possible implications with the different commercially available Latarjet fixation methods.

\section{Methods}

This study did not include live human subjects and therefore did not require Investigational Review Board or Ethical Committee approval.

A total of 163 intact skeletons of Greek male soldiers, who died during the Second World War, were examined by an anthropologist. Study inclusion criteria were scapulae with intact coracoid and glenoid anatomy and estimated age at the time of death between 20 and 30 years old with corresponding information, including gender and ethnicity. Exclusion criteria were the presence of any bone loss or osteophytes that could affect measurement reliability. A total of 101 skeletally mature bone specimens of scapulae from 97 skeletons were included in the study (4 skeletons had bilateral scapulae included).

The glenoid anterior-posterior dimension (glenoid width - GW) was measured at the point of greatest width, and the superior-inferior dimension (glenoid height - GH) was measured from the supraglenoid to the infraglenoid tubercle (Fig. 1). The coracoid was measured in three perpendicular dimensions: anteriorposterior (coracoid length - CL), medial-lateral (coracoid width - $\mathrm{CW}$ ) and superior-inferior (coracoid thickness -

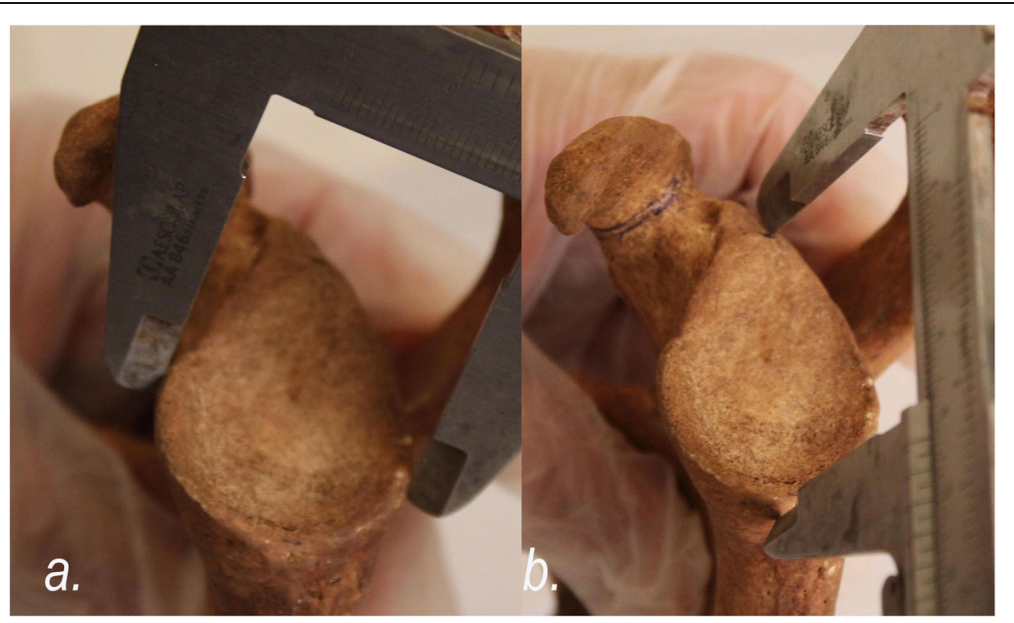

Fig. 1 The glenoid maximum (a) anterior-posterior (glenoid width - GW) and (b) the superior-inferior dimension (glenoid height - GH) are measured 
CTh) (Fig. 2). The coracoid length was measured from the tip to where the inferior cortex curves inferiorly (knee of the coracoid). The coracoid thickness and width were measured at a point $10 \mathrm{~mm}$ from the coracoid tip [13]. At this point was also located the thinnest part the coracoid. Therefore, we selected this point in order to mimic the coracoid thickness after flattening its inferior surface intra-operatively. All the measurements were made using a hand-held Vernier analog caliper with nominal precision of $0.1 \mathrm{~mm}$. In order to assess the intra-and inter-observer reproducibility of our measurements, 20 specimens were initially randomly chosen and measured by two of the authors.

In order to assess the ability of the transferred coracoid to restore the width of the glenoid during the classic Latarjet technique we created a hypothetical bone model and we calculated the glenoid width in the setting of $10 \%, 15 \%, 20 \%, 25 \%$ and $30 \%$ bone loss (Fig. 3). We next calculated the ratio of the bone available to restore the glenoid loss by dividing the coracoid thickness by the amount of bone lost in 10\%, 15\%, 20\%, 25\% and 30\% bone loss scenarios.

Furthermore, we chose to analyze four common surgical fixation techniques for the Latarjet procedure:

a. the Arthrex $3.75 \mathrm{~mm}$ titanium cannulated screw (Arthrex, Naples, FL, USA)

b. the Mitek $3.5 \mathrm{~mm}$ titanium cannulated BristowLatarjet Instability Shoulder Screw (Depuy Synthes Mitek Sports Medicine, Raynham, MA, USA)

c. the Synthes $4.5 \mathrm{~mm}$ steel Large Fragment LCP System Malleolar Screw (Synthes, West Chester, PA, USA)

d. the $2.8 \mathrm{~mm}$ Smith \& Nephew Round Button Latarjet Technique (Smith + Nephew, Inc. Andover, USA).

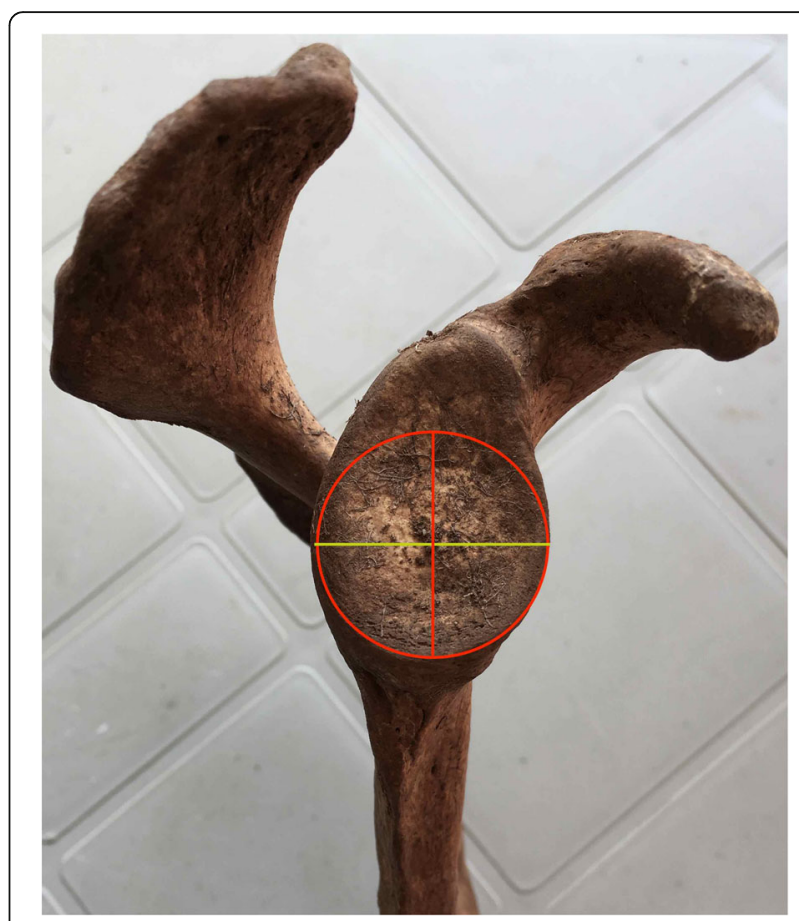

Fig. 3 The hypothetical glenoid bone loss was calculated using the Diameter-Based Method as follows: Percent bone loss $=($ Defect width/Diameter of inferior glenoid circle) $\times 100 \%$

In our hypothetical model, two implants (screws or buttons) were used to fix the coracoid to the glenoid, and the distance between the two holes was set at 10 $\mathrm{mm}$ for all types of fixation (Fig. 4). Thereafter, the distances from the superior-inferior and medio-lateral limits of the coracoid during the Latarjet procedure were calculated as follows:

1. Distance from the Supero-Inferior Limit $=[\mathrm{CL}-$ $(10+$ Implant Diameter $)] / 2$

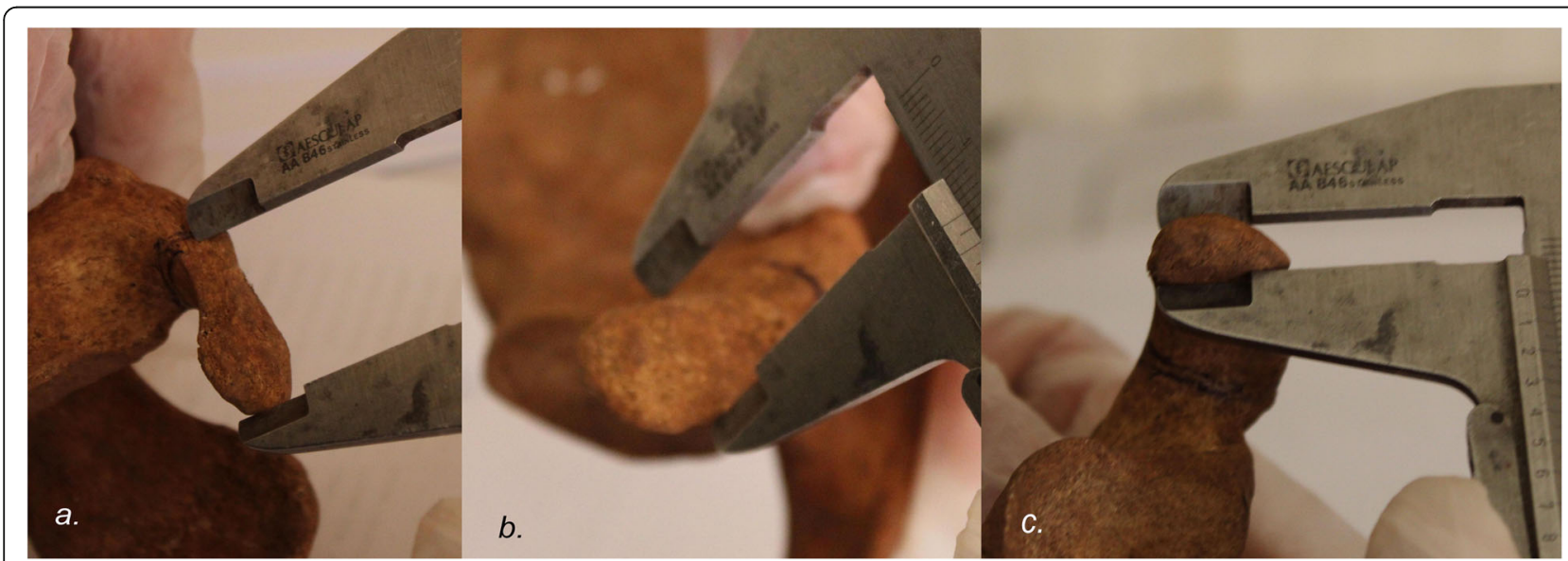

Fig. 2 The coracoid (a) anterior-posterior (coracoid length - CL), (b) medial-lateral (coracoid width - CW) and (c) superior-inferior (coracoid thickness - CTh) are measured 

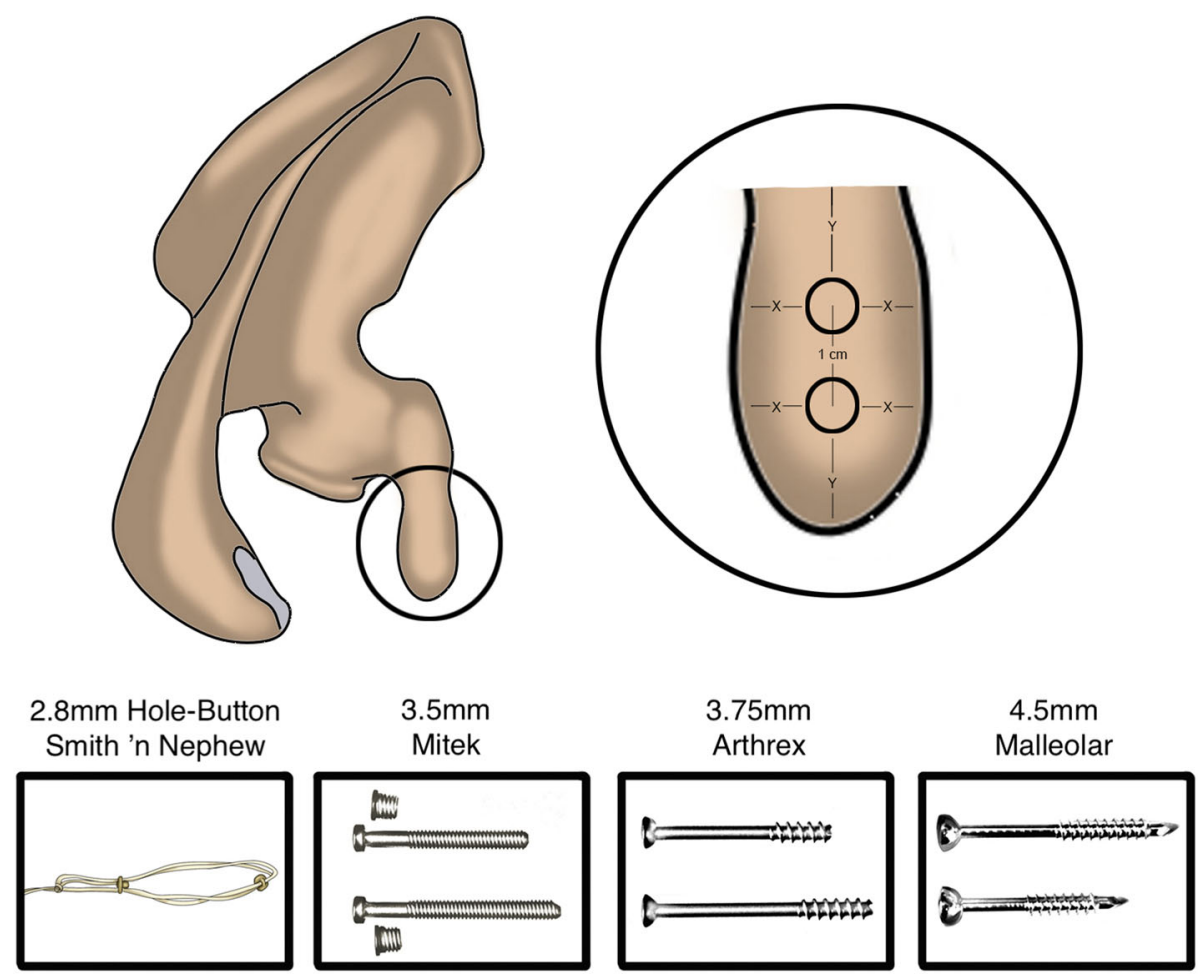

Fig. 4 Art design showing the harvested coracoid graft. The distance from the center of the two holes was set at $10 \mathrm{~mm}$. Y=Distance from the Supero-Inferior Limit. $X=$ Distance from the Medio-Lateral Limit. Also are shown the four common surgical fixation techniques for the Latarjet procedure

2. Distance from the Medio-Lateral Limit $=(\mathrm{CW}-\mathrm{Im}-$ plant Diameter)/2.

Furthermore, according to the $\mathrm{AO}$ principles, at the apex of a fracture fragment, the minimal distance between the screw head and the fracture line must be at least equal to the diameter of the screw head [14]. In the setting of the Latarjet procedure we hypothesized that the "safe distance" between the implant used and the coracoid osteotomy point should be at least equal to the diameter of the implant.

\section{Statistical analysis}

Continuous data were reported as mean with standard deviation and range. Categorical data were reported as percentages. Based on the Shapiro-Wilk test, major deviations from normality were revealed. Thereafter, continuous variables were compared with the nonparametric Spearman correlation or the MannWhitney $\mathrm{U}$ test, and categorical variables were compared with the chi-square test.

Intra and inter-observer agreement for $\mathrm{GW}, \mathrm{GH}, \mathrm{CL}$, $\mathrm{CW}$ and CTh were evaluated by the intraclass correlation coefficient (ICC or Kendall coefficient) 2-by-2 with a 95\% confidence interval. The power of ICC values was interpreted according to the Landis and Koch classification as no agreement to slight agreement, <0.20; fair agreement, 0.21 to 0.40 ; moderate agreement, 0.41 to 0.60 ; substantial agreement, 0.61 to 0.80 ; and almost perfect agreement, 0.81 to 1.00 .

Table 1 Intra- and inter-observers agreements measured by the Intraclass Correlation Coefficient (ICC), 2 by 2 with 95\% of confidence interval

\begin{tabular}{lll}
\hline & Intra-observer agreement & $\begin{array}{l}\text { Inter-observer agreement } \\
\text { ICC value }(95 \% \text { Cl) }\end{array}$ \\
\hline Glenoid Height (GH) & ICC value $(95 \% \mathrm{Cl})$ & $0.88(0.73-0.94)$ \\
Glenoid Width (GW) & $0.9(0.85-0.94)$ & $0.89(0.84-0.93)$ \\
Coracoid Length (CL) & $0.91(0.87-0.93)$ & $0.82(0.74-0.87)$ \\
Coracoid Width (CW) & $0.85(0.74-0.89)$ & $0.88(0.84-0.93)$ \\
Coracoid Thickness (CTh) & $0.91(0.85-0.95)$ & $0.91(0.86-0.94)$ \\
\hline
\end{tabular}




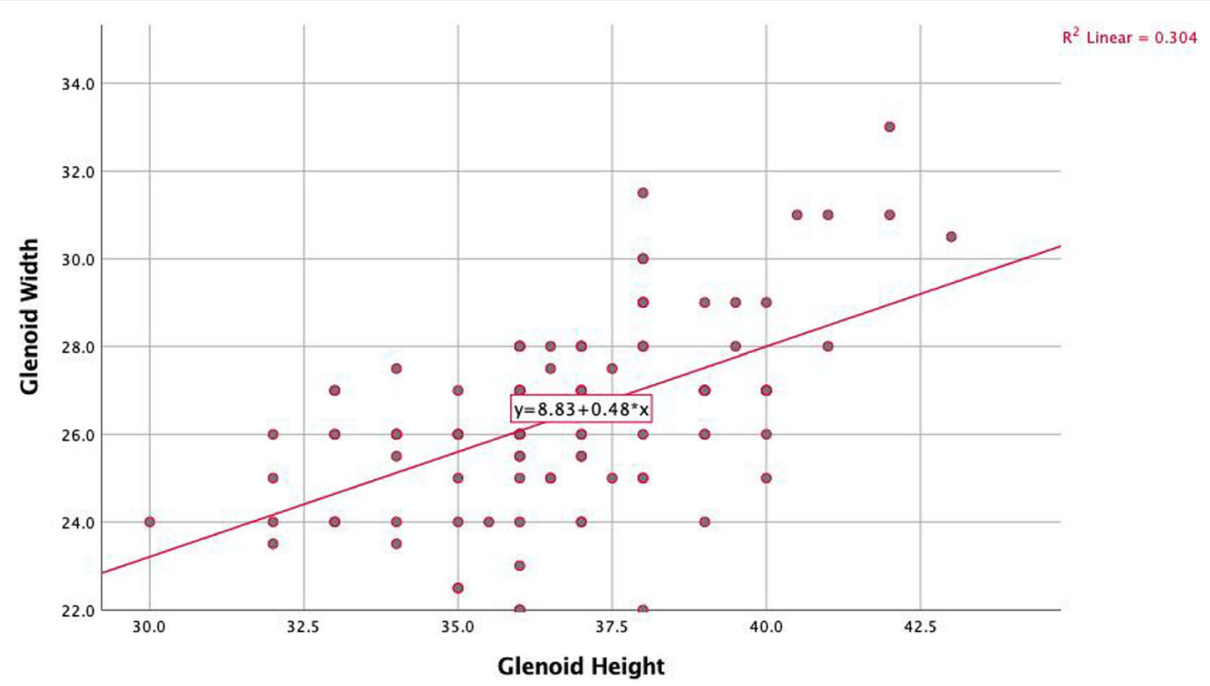

Fig. 5 A strong positive correlation between the height and the width of the glenoid was observed $($ rho $=0.53, P<.001)$

Statistical significance was set at $p<.05$, and the analysis was performed using SPSS (v 25.0; IBM Corp).

\section{Results}

Intra and inter-observer reliability tests

The intra and inter-observer agreement for the $\mathrm{GH}$ and GW were almost perfect. The intra and inter-observer agreement for the CL, CW and CTh were substantial to almost perfect (Table 1).

\section{Glenoid and coracoid dimensions}

The mean GH was $36.7 \pm 2.5 \mathrm{~mm}$ (range $43-30 \mathrm{~mm}$ ) and the mean GW was $26.4 \pm 2.2 \mathrm{~mm}$ (range $22-33 \mathrm{~mm}$ ). The mean CL was $23.9 \pm 3 \mathrm{~mm}$ (range $14-30 \mathrm{~mm}$ ), the mean CW was $13.6 \pm 2 \mathrm{~mm}$ (range $6-21 \mathrm{~mm}$ ), and the mean CTh was $8.7 \pm 1 \mathrm{~mm}$ (range $5.5-13 \mathrm{~mm}$ ). The CL was in $46 \%$ of the cases $<25 \mathrm{~mm}(21.4 \pm 2 \mathrm{~mm}$, range 14-23.5 $\mathrm{mm})$.

A strong positive correlation between the height and the width of the glenoid was observed ( $\mathrm{rho}=0.53$,
$P<.001$ ) (Fig. 5). Regarding the coracoid, a positive correlation was found between its length (CL) and width $(\mathrm{CW})$ (rho $=0.24, p=0.016$ ). No correlations were found between the CTh and the CL (rho $=0.145, p=0.15)$ and the CTh and the CW (rho $=0.19, p=0.06$ ).

Furthermore, a positive correlation was found between the $\mathrm{GH}$ and the $\mathrm{CL}(\mathrm{rho}=0.3, p=0.002)$ and between the GW and the CW (rho $=0.45, p<0.001$ ) (Fig. 6a, b). No correlations were observed between the GW and the CTh $($ rho $=0.135, p=0.181)$.

\section{Glenoid bone loss restoration}

In all cases with $10 \%, 15 \%$ and $20 \%$ of glenoid bone loss, the coracoid graft positioned with the classic Latarjet technique was able to restore glenoid width. The respective ratios are shown in Table 2. Also, in cases with $25 \%$ and $30 \%$ bone loss, the coracoid graft was thick enough to restore the glenoid anatomy in $96 \%$ and $80 \%$ of the cases. The ratios are also shown in Table 2.
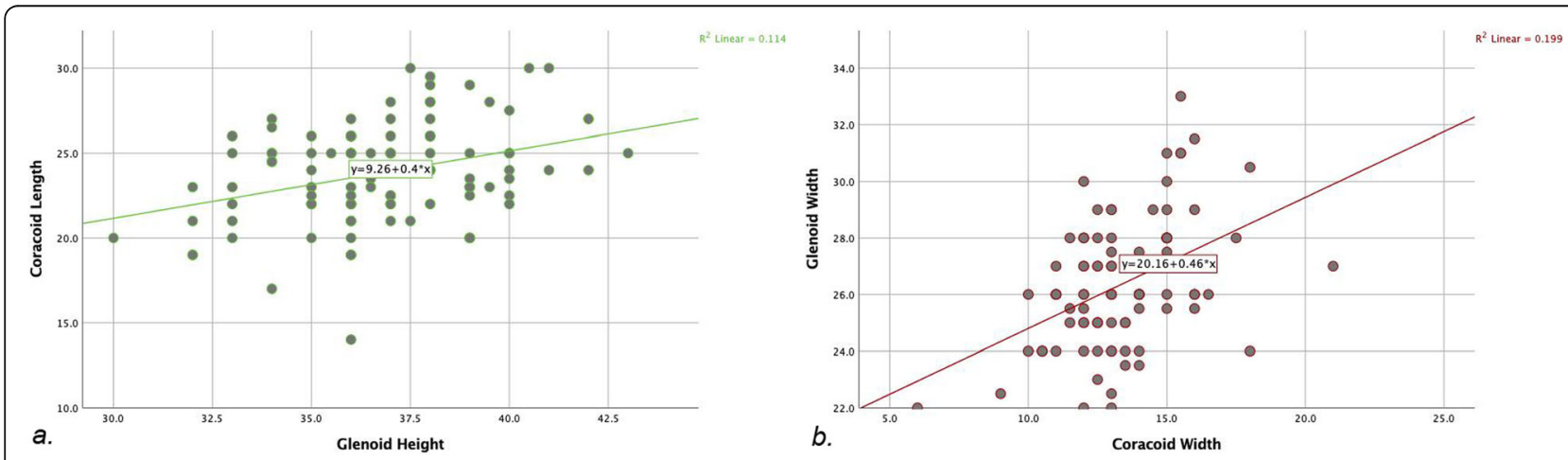

Fig. 6 A positive correlation was found between (a) the $\mathrm{GH}$ and the $\mathrm{CL}(\mathrm{rho}=0.3, p=0.002)$ and (b) between the $\mathrm{GW}$ and the $\mathrm{CW}$ $($ rho $=0.45, p<0.001)$ 
Table 2 Overall results according to Glenoid Bone Loss

\begin{tabular}{llllll}
\hline Glenoid Bone Loss & $\mathbf{1 0 \%}$ & $\mathbf{1 5 \%}$ & $\mathbf{2 0 \%}$ & $\mathbf{2 5 \%}$ & $\mathbf{3 0 \%}$ \\
\hline Restoration of Glenoid Anatomy (Percentage of Cases) & $100 \%$ & $100 \%$ & $100 \%$ & $96 \%$ & $76.2 \%$ \\
Bone Coverage Ratios & $3.3 \pm 0.6(2.3-5.4)$ & $2.2 \pm 0.4(1.5-3.6)$ & $1.7 \pm 0.3(1.2-2.7)$ & $1.3 \pm 0.2(0.9-2.2)$ & $1 \pm 0.03(0.8-1.8)$
\end{tabular}

\section{Implications for different Latarjet techniques}

The distance from the superior or inferior border of the coracoid of the 4 different implants types, according to the technique used, are presented in Table 3. With the use of the $2.8 \mathrm{~mm}$ Smith + Nephew Round Button the "safe distance" was ensured in $98 \%$ of the cases. With the use of the originally proposed $4.5 \mathrm{~mm}$ malleolar screws this "safe distance" was present in $56 \%$ of the cases, with the $3.75 \mathrm{~mm}$ Arthrex screws in $85 \%$ and with the Mitek $3.5 \mathrm{~mm}$ screws in $87 \%$ of the cases respectively.

Furthermore, the distance of the 4 different implants from the medio-lateral borders of the coracoid are also presented in Table 3.

\section{Discussion}

The first main finding of our study was that the mean coracoid bone graft length available for transfer (from the coracoid tip to where the inferior cortex curves inferiorly) in our young population was $23.9 \pm 3 \mathrm{~mm}$. Therefore, in $46 \%$ of the cases there was less than the ideal length of $25 \mathrm{~mm}$, according to the original technique $[11,15]$. Previous reports have shown divergent results regarding the maximal harvestable coracoid length. Dolan et al. and Shibata et al. reported in cadaver studies that the mean maximum length available for transfer was $28.5 \mathrm{~mm}$ [16] and $27 \mathrm{~mm}$ [17] respectively. Furthermore, Paladini et al. in computed tomography study and Young et al. in an intra-operative measurement study, found the available coracoid length to be $26.3 \mathrm{~mm}$ and $26.4 \mathrm{~mm}$ respectively [18]. However, Bhatia et al. and Lian et al. reported values of $19 \mathrm{~mm}$ and 24 $\mathrm{mm}$ respectively $[19,20]$. From the aforementioned studies and the international literature, the coracoid length seems to be positively affected by male gender, age, overall height and Caucasian genetics [12, 13, 17, $20,21]$. In our study population, the height of the cadavers was not available, however we observed a positive correlation with the glenoid height.
The second main finding was that the harvestable coracoid length directly affects the position and possibly the biomechanics of the different implants used during fixation in the Latarjet procedure. Based on the AO principles we hypothesized that when the distance between the implant and the coracoid osteotomy is at least equal to the diameter of the implant, it would be "safe", with low fracture risk. Therefore, complications such as acute coracoid fracture or later osteolysis could be avoided [10]. With the use of the originally proposed $4.5 \mathrm{~mm}$ malleolar screws this "safe distance" was ensured only in $56 \%$ of the cases. This percentage was significantly improved with smaller screws or the use of cortical button fixation. Despite this, no studies exist comparing the different types of fixation. This could explain the shortterm differences in coracoid fracture and osteolysis when $4.5 \mathrm{~mm}$ screw fixation $[22,23]$ is compared to button fixation [24, 25]. However, when Boileau et al. perform their Latarjet technique, only $15 \mathrm{~mm}$ of the coracoid is harvested and fixation is with only one button [24]. In our study, for homogeneity reasons, we created a hypothetical model in which the complete coracoid is harvested and there are two points of fixation.

Furthermore, we found that the coracoid graft thickness is able to restore the glenoid anatomy in most of the cases when the classic Latarjet technique was performed. The mean "filling ratio" could be 3.3 to 1.7 in cases with smaller glenoid bone loss (10\% to $20 \%)$ and 1.3 in most of the cases with defects of $25 \%$. This extension of concavity of the glenoid articular arc may better manage the bipolar-"off-track" lesions [26] and explains the favorable clinical outcomes and the lower recurrence rates when the Latarjet procedure is performed in cases with even $13.5 \%$ glenoid bone loss $[6,27]$. However, we found that in cases with $30 \%$ glenoid bone loss, the coracoid graft was not always enough to achieve a "filling ratio" of 1.0 (20\% of the cases). Hantes et al. reported similar results in their cadaveric study. In intact glenoids with a mean area of $734 \pm 89 \mathrm{~mm}^{2}$, they created a defect of $29 \%$. After the reconstruction, the mean surface area

Table 3 Distance from Coracoid Borders According to Implant Type

\begin{tabular}{|c|c|c|c|c|c|}
\hline & 2.8 mm Smith 'n Nephew & 3.5 mm Mitek Depuy & $3.75 \mathrm{~mm}$ Arthrex & $4.5 \mathrm{~mm}$ Malleolar & $P$ values \\
\hline $\begin{array}{l}\text { Supero-Inferior } \\
\text { Distance }\end{array}$ & $\begin{array}{l}5.5 \pm 1.5 \mathrm{~mm}(0.6 \text { to } 8.6 \\
\mathrm{mm})\end{array}$ & $\begin{array}{l}5.2 \pm 1.5 \mathrm{~mm}(0.3 \text { to } 8.3 \\
\mathrm{mm})\end{array}$ & $5 \pm 1.5 \mathrm{~mm}(0.1$ to $8 \mathrm{~mm})$ & $\begin{array}{l}4.7 \pm 1.5 \mathrm{~mm}(-0.3 \text { to } 7.8 \\
\mathrm{mm})\end{array}$ & $\begin{array}{l}P< \\
0.001^{\#}\end{array}$ \\
\hline Medio-Lateral Distance & $5.4 \pm 1 \mathrm{~mm}(1.6$ to $9.1 \mathrm{~mm})$ & $5 \pm 1 \mathrm{~mm}(1.3$ to $8.8 \mathrm{~mm})$ & $\begin{array}{l}4.9 \pm 1 \mathrm{~mm}(1.1 \text { to } 8.6 \\
\mathrm{mm})\end{array}$ & $4.5 \pm 1 \mathrm{~mm}(0.8$ to $8.3 \mathrm{~mm})$ & $\begin{array}{l}P< \\
0.001^{\#}\end{array}$ \\
\hline
\end{tabular}

$\#=p$ value of Friedman test 
of the glenoid was still smaller $\left(708 \pm 71 \mathrm{~mm}^{2}\right)$, but this was not statistically significant [28]. Furthermore, the authors found that the coracoid thickness represents $27 \pm 5 \%$ of the intact glenoid [28].

In a clinical study, Moon et al. operated on 44 patients with large glenoid defects of $25.3 \% \pm 6 \%$ of the intact glenoid surface. Using 3-D CT-scans, they found $1.5 \pm$ $2 \%$ recurrent bone defect, however, this did not affect the clinical outcome [29]. Also, Paladini et al., in 23 patients with glenoid defects greater than $20 \%$, found that the coracoid filled the defect by $102 \%$ [18]. These small differences in filling the defect in published studies could be due to differences in age, race and patient height [13, $20]$. However, when the glenoid bone loss is $\geq 30 \%$ the "congruent arc"- modified Latarjet [12] or the EdenHybinette procedure [7] could be preferred. Regarding the "congruent arc" technique, our results also showed that it may be indicated in greater defects, as the coracoid width was always greater that the coracoid thickness.

Young et al. performed the classic Latarjet technique with $4.5 \mathrm{~mm}$ malleolar screws, and during their intraoperative measurements, found that the distance from the edge of the inferior drill hole to the lateral margin of the graft was $5.7 \pm 1.1 \mathrm{~mm}$ [30]. Sahu et al., also using $4.5 \mathrm{~mm}$ screws in their cadaveric study, found that this "lateral offset" of the coracoid graft was $5.5 \pm 1 \mathrm{~mm}$ [31]. Our study results were similar, when using screw fixation. However, surgeons should be careful when the drill holes are placed in the middle of the coracoid and smaller implants are used. In these cases the "lateral offset" could be increased (by up to $9 \mathrm{~mm}$ ).

\section{Strengths and limitations}

In this anthropometric study we tried to describe the possible implications between the coracoid process dimensions and the different surgical techniques. A strength of this study is the young male population (soldiers from the Second World War) that corresponds to the type of patients commonly operated on for shoulder instability. However, we cannot take into account the evolution of the Greek population over time, and nowadays larger glenoid and coracoid dimensions could be present within the population. Despite the measurements being reproducible (intra and inter-observer reliability), this was not a cadaveric study and the soft tissue insertions (pectoralis minor, coracoclavicular and acromioclavicular ligaments) were not present. Also, other anthropometric details of the specimens (like the height) were not available. The glenoid bone loss and the application of different materials were performed by using a "hypothetical" model and not in real practice. Finally, for homogeneity reasons all measurements were performed regarding the classic Latarjet technique and not the congruent arc or the Bristow technique.

\section{Conclusions}

The harvested coracoid graft during the classic Latarjet procedure is adequate to restore up to $25 \%$ glenoid defects. However, in cases with bone loss greater than $30 \%$, the coracoid graft is not always enough to reconstruct the normal surface area of the glenoid. Furthermore, in $46 \%$ of our specimens the harvestable coracoid length was smaller that $25 \mathrm{~mm}$. Therefore, surgeons should be cautious when using larger implants ( $4.5 \mathrm{~mm}$ screws) that could be positioned too close to the osteotomy, creating a fracture risk. Finally, the distance from the medio-lateral limit of the coracoid could be significantly increased (up to $9 \mathrm{~mm}$ ) when smaller-button implants are used. The Latarjet procedure is technically demanding and the pre and peri-operative planning with careful measurement of the glenoid and coracoid dimensions is mandatory for clinical success.

\section{Abbreviations}

GL: Glenoid Length; GW: Glenoid Width; CL: Coracoid Length; CW: Coracoid Width; CTh: Coracoid Thickness

\section{Acknowledgments}

The authors would also like to thank Mr. Argyris Koromilas for the medical equipment provided during the study.

\section{Authors' contributions}

The authors read and approved the final manuscript

\section{Competing interests}

The authors declare that they have no competing interests.

\section{Author details}

${ }^{1}$ Department of Orthopedic Surgery, 401 Military Hospital of Athens, Athens, Greece. ${ }^{2}$ Department of Orthopaedic Surgery, Centre Osteoarticulaire des Cèdres, Parc sud galaxie, 5 Rue Des Tropiques, 38130 Echirolles, Grenoble, France.

Received: 21 December 2019 Accepted: 4 March 2020

Published online: 17 March 2020

\section{References}

1. Assunção JH, Malavolta EA, de Souza FJ, Gracitelli MEC, Ferreira Neto AA (2019) Anterior Glenohumeral instability: systematic review of outcomes assessment used in Brazil. Rev Bras Ortop (Sao Paulo) 54:483-490

2. Zimmermann SM, Scheyerer MJ, Farshad M, Catanzaro S, Rahm S, Gerber C (2016) Long-term restoration of anterior shoulder stability: a retrospective analysis of arthroscopic Bankart repair versus open Latarjet procedure. J Bone Joint Surg Am 98:1954-1961

3. Latarjet M (1954) Treatment of recurrent dislocation of the shoulder. Lyon Chir 49:994-997

4. Patte D, Debeyre J (1980) Luxations récidivantes de l'épaule. Encycl Med Chir Paris-Technique chirurgicale 44265:4

5. Yamamoto N, Muraki T, An K-N, Sperling JW, Cofield RH, Itoi E, Walch G, Steinmann SP (2013) The stabilizing mechanism of the Latarjet procedure: a cadaveric study. J Bone Joint Surg Am 95:1390-1397

6. Jeon YS, Jeong HY, Lee DK, Rhee YG (2018) Borderline Glenoid bone defect in anterior shoulder instability: Latarjet procedure versus Bankart repair. Am J Sports Med 46:2170-2176

7. Rabinowitz J, Friedman R, Eichinger JK (2017) Management of Glenoid Bone Loss with anterior shoulder instability: indications and outcomes. Curr Rev Musculoskelet Med 10:452-462

8. Shin S-J, Kim RG, Jeon YS, Kwon TH (2017) Critical value of anterior Glenoid bone loss that leads to recurrent Glenohumeral instability after arthroscopic Bankart repair. Am J Sports Med 45:1975-1981

9. Thomazeau H, Courage O, Barth J, Pélégri C, Charousset C, Lespagnol F, Nourissat G, Audebert S, Guillo S, Toussaint B, Lafosse L, Bradel J, Veillard D, 
Boileau P (2010) Can we improve the indication for Bankart arthroscopic repair? A preliminary clinical study using the ISIS score. Orthop Traumatol Surg Res 96:S77-S83

10. Domos P, Lunini E, Walch G (2018) Contraindications and complications of the Latarjet procedure. Shoulder Elbow 10:15-24

11. Plancher KD, Petterson SC, Walch G (2013) Open Latarjet: a reliable, successful method to prevent recurrence in the presence of bony defects. Oper Tech Sports Med 21:238-245

12. Joshi D, Gupta LM, Tanwar M, Lal A, Chaudhary D (2018) Anthropometric and radiologic measurements of coracoid dimensions and clinical implications in an Indian population. Orthop J Sports Med 6:232596711876163

13. Knapik DM, Cumsky J, Tanenbaum JE, Voos JE, Gillespie RJ (2018) Differences in coracoid and Glenoid dimensions based on sex, race, and age: implications for use of the Latarjet technique in Glenoid reconstruction. HSS J 14:238-244

14. Buckley R, Moran C, Apivatthakakul T (2018) AO Principles of Fracture Management, Vol. 1: Principles. ISBN:9783132423091

15. Young AA, Maia R, Berhouet J, Walch G (2011) Open Latarjet procedure for management of bone loss in anterior instability of the glenohumeral joint. J Shoulder Elb Surg 20:S61-S69

16. Dolan CM, Hariri S, Hart ND, McAdams TR (2011) An anatomic study of the coracoid process as it relates to bone transfer procedures. J Shoulder Elb Surg 20:497-501

17. Shibata T, Izaki T, Miyake S, Doi N, Arashiro Y, Shibata Y, Irie Y, Tachibana K, Yamamoto $T$ (2019) Predictors of safety margin for coracoid transfer: a cadaveric morphometric analysis. J Orthop Surg Res. 114(1):174. https://doi. org/10.1186/s13018-019-1212-z

18. Paladini P, Singla R, Merolla G, Porcellini G (2016) Latarjet procedure: is the coracoid enough to restore the glenoid surface? Int Orthop 40:1675-1681

19. Bhatia S, Frank RM, Ghodadra NS, Hsu AR, Romeo AA, Bach BR, Boileau P, Provencher MT (2014) The outcomes and surgical techniques of the Latarjet procedure. Arthroscopy 30:227-235

20. Lian J, Dong L, Zhao Y, Sun J, Zhang W, Gao C (2016) Anatomical study of the coracoid process in Mongolian male cadavers using the Latarjet procedure. J Orthop Surg Res 11(1):126. https:/doi.org/10.1186/s13018-016-0461-3

21. Fathi M, Cheah P-S, Ahmad U, Nasir MN, San AA, Abdul Rahim E, Hussin P, Mahmud R, Othman F (2017) Anatomic Variation in Morphometry of Human Coracoid Process among Asian Population. Biomed Res Int 2017: 6307019. https://doi.org/10.1155/2017/6307019

22. Haeni DL, Opsomer G, Sood A, Munji J, Sanchez M, Villain B, Walch G, Lafosse L, Société Française d'Arthroscopie (2017) Three-dimensional volume measurement of coracoid graft osteolysis after arthroscopic Latarjet procedure. J Shoulder Elb Surg 26:484-489

23. Pereira AC, Gutierres M (2017) Complications of coracoid transfer procedures for the treatment of recurrent shoulder dislocation. Porto Biomed J 2:161-166

24. Boileau P, Saliken D, Gendre P, Seeto BL, d'Ollonne T, Gonzalez J-F, Bronsard N (2019) Arthroscopic Latarjet: suture-button fixation is a safe and reliable alternative to screw fixation. Arthroscopy 35:1050-1061

25. Gendre P, Thélu C-E, d'Ollonne T, Trojani C, Gonzalez J-F, Boileau P (2016) Coracoid bone block fixation with cortical buttons: An alternative to screw fixation? Orthop Traumatol 102:983-987

26. Di Giacomo G, Itoi E, Burkhart SS (2014) Evolving concept of bipolar bone loss and the hill-Sachs lesion: from "engaging/non-engaging" lesion to "ontrack/off-track" lesion. Arthroscopy 30:90-98

27. Shaha JS, Cook JB, Song DJ, Rowles DJ, Bottoni CR, Shaha SH, Tokish JM (2015) Redefining "critical" bone loss in shoulder instability: functional outcomes worsen with "subcritical" bone loss. Am J Sports Med 43 1719-1725

28. Hantes ME, Venouziou A, Bargiotas KA, Metafratzi Z, Karantanas A, Malizos KN (2010) Repair of an anteroinferior glenoid defect by the latarjet procedure: quantitative assessment of the repair by computed tomography. Arthroscopy 26:1021-1026

29. Moon SC, Cho NS, Rhee YG (2015) Quantitative assessment of the Latarjet procedure for large Glenoid defects by computed tomography: a coracoid graft can sufficiently restore the Glenoid arc. Am J Sports Med 43:1099-1107

30. Young AA, Baba M, Neyton L, Godeneche A, Walch G (2013) Coracoid graft dimensions after harvesting for the open Latarjet procedure. J Shoulder Elb Surg 22:485-488
31. Sahu D, Jagiasi J (2019) Intraoperative and anatomic dimensions of the coracoid graft as they pertain to the Latarjet-Walch procedure. J Shoulder Elb Surg 28:692-697

\section{Publisher's Note}

Springer Nature remains neutral with regard to jurisdictional claims in published maps and institutional affiliations.

\section{Submit your manuscript to a SpringerOpen ${ }^{\circ}$ journal and benefit from:}

- Convenient online submission

- Rigorous peer review

- Open access: articles freely available online

- High visibility within the field

- Retaining the copyright to your article

Submit your next manuscript at $>$ springeropen.com 